\title{
Below the surface: Parents' views on the factors that influence treatment adherence in paediatric burn scar management - a qualitative study
}

\section{Introduction}

In 20117634 people were admitted to hospital for the treatment of burn injuries in England and Wales (1). Of these, $48 \%$ were aged below sixteen years, the age group most at risk of burn injury (1). For some children and parents, the burn incident results in physical and emotional challenges that may have life changing implications (2). For parents, the unexpected and often shocking changes to family dynamics are traumatic and require major adaptation to everyday tasks and duties (3). At the same time parents have an important role to play in treatment maintenance and therefore subsequent outcomes for their children (4).

Research into the experiences of parents during initial resuscitation and acute rehabilitation following a burn injury demonstrates that this time is extremely stressful, characterised by uncertainty, fear (5) and high levels of distress $(6,7)$. Following discharge, rehabilitation may require long term treatment that seeks to reduce the impact of scarring for functional and aesthetic reasons. This can include scar management modalities such as pressure garment therapy (PGT) and creaming and massage that require high levels of adherence for optimal outcomes (8). At this stage of treatment there is often less contact with clinical staff and less is known about parents' experiences. There is a lack of research describing factors that may influence treatment adherence in scar management (9). Recent studies of adult patients' experiences of scar management give some insight into the lived realities of treatment, and how patients seek to maintain regimes $(10,11)$. Whilst PGT can be perceived as burdensome, adult patients also report benefits, including feelings of physical and psychological protection afforded by garments $(10,11)$. However, the complexities of maintaining paediatric scar management are different as the burden of care often lies with the parent caregiver as well as the patient (12). Indeed, there is need for a 'therapeutic triad', with interactions between professionals, parents and children being key to attempts to maintain treatment. For some parents the realities of a demanding treatment agenda within day-to-day life, set against the intense psycho-social impacts of a child's burn injury may make this especially difficult (13).

Here we present the findings of qualitative research that has investigated parents' experience of scar management therapy and their attempts to maintain treatment at home. The aim of this paper is to 
outline parents' views on the factors that influence scar management treatment adherence following discharge.

\section{Methods}

\section{Study design}

This qualitative research formed part of a wider mixed-methods feasibility study of PGT for the prevention of abnormal scarring after burn injury in adults and children (PEGASUS) $(14,15)$. One of the aims of the integrated qualitative research was to understand adult patients' and parents' experiences of scar management therapies, and predominantly PGT.

\section{Sampling and recruitment}

The sample consists of parents/ carers (referred to as parents from this point) of paediatric burns patients aged 0-9 years who had at least six months' experience of PGT and had finished PGT no more than two years prior to data collection, or were a participant in a pilot trial of PGT that formed part of the PEGASUS study. Paediatric patients participating in the pilot trial were allocated to scar management with or without PGT. Participants were recruited by occupational therapists (OTs) and/ or research nurses (RNs) in 3 of the PEGASUS pilot trial sites across England: Birmingham Children's Hospital, Royal Manchester Children's Hospital, and Queen Victoria Hospital, East Grinstead. Clinical staff provided information sheets to potential interviewees and took written consent to pass participant contact details on to the PEGASUS qualitative research team. A member of the qualitative research team then contacted potential interviewees, provided further information and answered questions as necessary, before arranging a suitable time, date and venue for the interview. Written informed consent was gained from all participants prior to the start of data collection.

\section{Ethics}


A favourable opinion for the PEGASUS study was received from the West Midlands: Coventry and Warwickshire Research Ethics Committee (14/WM/0160).

\section{Data collection}

Semi-structured interviews were identified as an appropriate data collection method given that they facilitate an in-depth exploration of participant views (16) and are particularly useful in discussions of sensitive or traumatic experiences. Interviews were conducted by a trained non-clinical qualitative researcher who was independent of the child's clinical care team. Interviews were mainly conducted in the patient's home, which was the preferred venue; although a small number took place via telephone. A semi-structured discussion guide was developed based on the literature, discussions with our patient and public involvement (PPI) group, and the wider PEGASUS research team. The semi-structured interviews were conducted in a participant-focused manner allowing issues and perspectives important to participants to emerge naturally (17). Topics discussed included; accounts of the accident and injury (where participants were happy to talk about these in order to provide context for the remainder of the data); accounts of subsequent treatment; the experience of PGT and other scar management techniques; hopes and expectations for treatment, recovery and scar management; perspectives on a trial of PGT, and patient-centred outcomes. The topic guide and interview process was refined after reflection on a small sample of initial interviews. Following this, data collection and analysis took place iteratively (17) and continued until the research team judged that the data and sample had sufficient depth and breadth to address the research questions (18). At the end of each interview, participants were asked to complete a short demographic questionnaire to facilitate maximum variation sampling and a description of the sample characteristics.

\section{Data analysis}


Interviews were digitally audio-recorded and transcribed clean verbatim by a specialist company.

Data were analysed using an inductive thematic approach, following the six steps proposed by Braun and Clarke (19). Initially, transcripts were read repeatedly to aid familiarisation and allow for data immersion. This facilitated the generation of preliminary codes and themes supported by the use of NVivo software, which eventually progressed into a developed coding frame. A sample of transcripts was independently double-coded by two authors (NA and JM) and additional interpretations were incorporated into the coding frame.

\section{Findings}

\section{Sample Characteristics}

A total of 22 interviews were conducted with 25 participants (including 3 couples), lasting between 21 and 77 minutes (average 44 minutes). Of these, 18 were mothers and 7 fathers, of 17 boys and 6 girls aged 1-9 years (Table 1). One parent had two children with a burn injury. The most common type of burn injury was reported as scald, with total body surface area of the burn ranging from 1$60 \%$. Of the 23 children, 9 were participants in the pilot trial, and 5 of these were allocated to receive PGT. A further 2 children allocated to 'no PGT' were later treated with pressure garments during pilot trial follow up. Therefore, 21 of the 23 children had received PGT. 
Table 1: Sample characteristics

\begin{tabular}{|c|c|c|}
\hline \multirow{2}{*}{ Gender of parent } & Male & $7(28.0)$ \\
\hline & Female & $18(72.0)$ \\
\hline \multirow{2}{*}{ Gender of child } & Boy & 17 (73.9) \\
\hline & Girl & $6(26.1)$ \\
\hline \multirow{5}{*}{ Age of parent* } & $<21$ & $0(0.0)$ \\
\hline & $21-30$ & $6(27.3)$ \\
\hline & $31-40$ & $13(59.1)$ \\
\hline & $41-50$ & $2(9.1)$ \\
\hline & $51-60$ & $1(4.5)$ \\
\hline \multirow{3}{*}{$\begin{array}{l}\text { Age of child (at the } \\
\text { time of interview) }\end{array}$} & $<1$ & $0(0.0)$ \\
\hline & $1-5$ & $14(60.9)$ \\
\hline & $6-9$ & 9 (39.1) \\
\hline \multirow{4}{*}{ Ethnicity of parent* } & White & $16(72.7)$ \\
\hline & $\begin{array}{l}\text { Black African/ Caribbean/ } \\
\text { Black British }\end{array}$ & $2(9.1)$ \\
\hline & Asian/ Asian British & $2(9.1)$ \\
\hline & Other & $2(9.1)$ \\
\hline \multirow{5}{*}{ Type of burn } & Flame & $5(21.7)$ \\
\hline & Scald & $15(65.2)$ \\
\hline & Contact & $2(8.7)$ \\
\hline & Friction & $1(4.3)$ \\
\hline & Electrical & $0(0.0)$ \\
\hline \multirow{7}{*}{ TBSA of burn (\%) } & $0-10$ & $10(43.5)$ \\
\hline & $11-20$ & $6(21.7)$ \\
\hline & $21-30$ & $3(13.0)$ \\
\hline & $31-40$ & $0(0.0)$ \\
\hline & $41-50$ & $0(0.0)$ \\
\hline & $>50$ & $1(4.3)$ \\
\hline & Don't know & $3(13.0)$ \\
\hline
\end{tabular}

* age / ethnicity of parent completing the background information questionnaire

\section{Themes}

Here we describe four overarching themes (Figure 1) that give insight into parents' experiences of scar management therapy and adherence. The first, transition from hospital to home, provides context for the subsequent themes;

- the practical realties of treatment; 
- the emotional labour involved in treatment and;

- negotiating treatment and regime.

- Move from acute care

- Return to normality

-A new aspect to the parenting role

Transition from hospital to home

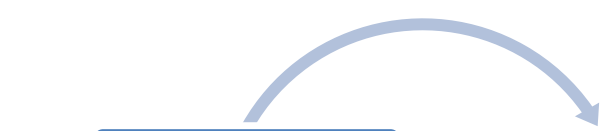

\section{Practical realities}

- Developing a routine

- Division of care

labour

- Hospital

appointments
-Treatment signification

-Managing children's emotions -Imagining the future

\section{Emotional labour}

Negotiating treatment and regime

- Practical realities + Emotional labour = Treatment negotiation and regime maintenence

\section{Figure 1: Thematic presentation}

\section{Transition from hospital to home}

\section{Move from acute care}

For all of the parents interviewed, the time spent in hospital with their child during the initial acute stage of treatment was extremely traumatic and distressing:

"Obviously up until [inpatient discharge] the whole thing has been absolutely horrific".

(BCP07, father; boy aged 5)

In many cases, due to the immediate clinical need to preserve life and/or function for the child, parents reported feeling a loss of control as they were unable to maintain their role as primary caregivers. Often memories of this time were blurred and unclear. For example, during a joint interview, there seemed to be some uncertainty between mother and father around the duration of the inpatient stay:

"Father: He was only actually admitted to the ward for two weeks.

Mother: I don't think he was, because he had an operation [...] 
Father: It must have seemed like two months to you, because you were there every night, but no it was two weeks." (BC03, mother \& father; boy aged 3)

Parents' discussions of their experience of acute care were often rooted in expressions of fear and concern for their child and a deep reliance on healthcare professionals. As such, the moment of inpatient discharge was described as pivotal by parents as their child had recovered sufficiently to be allowed to go home. However, some parents also spoke of apprehension when leaving the hospital:

"I didn't want to go home, I was scared to go home [...] I've always felt quite safe [in the hospital], and I've always got comfort when I've seen nurses or staff." (BCP08, mother; boy aged 8)

\section{Return to normality}

The desire of parents to take their child home so that they and their children could return to some sense of normality was expressed by many:

"We liked the idea of a return to normality for him and his psychological adjustment to what he had been through." (BCP05, father; boy aged 3)

At this stage parents are required to be more active in treatment regimes. For some, this can mean restoring some sense of normality with regard to aspects of the parental role (e.g. control as primary caregiver) that were lost during acute treatment. Interviewees reported acts, such as researching treatment options for their child and having input to treatment decisions that may be central to a return to the traditional parenting dynamic:

"I went online and tried to see what the state of the art was. So it fitted with what we were told, was happy to follow." (EC01, father; boy aged 5)

For some parents, their scar management treatment preferences seemingly reflect their views as to how treatment options might help attain some sense of normality during the transition from hospital to home. For example, this father described why he and his wife had thought that massage and creaming would best enable the transition from hospital to home, and an associated sense of normality: 
"I think we both liked the idea of a non-pressure garment treatment because he would feel more normal sooner. If he went with a pressure garment it would be extending that bandage feeling, and that there's still, it feels like there's still, something special going on here, there's something out of the ordinary happening with the pressure garment." (BCP05, father; boy aged 3)

Other parents thought that regaining a sense of normality might best be achieved via PGT. The scar area would be covered by a barrier offering physical protection for the area allowing children to do normal things. It would also cover the scarring from sight offering some emotional relief from the visual reminder that it may invoke.

\section{A new aspect to the parenting role}

Within this transition from hospital to home there was a need for parents to take on the role of therapeutic caregiver with responsibility for maintaining treatment. The emotional impact of the burn incident and the discomfort that may be expressed by the child during treatment (see emotional labour section) made this difficult. Some parents spoke of a conflict of care roles, between the nurturing parent and the clinical caregiver. They reported finding this conflict sometimes hard to express to healthcare staff when discussing issues of treatment adherence. When reflecting on the first few days at home with her son, one mother expressed the difficulty in undertaking massage and creaming:

"It was really hard at first because his skin was sensitive, so it was hard, and because we were at the hospital every week, sometimes twice a week, and then they're asking me this question and how is it going, and you've got to do this, and I just felt like this pressure, don't you understand what I'm saying, his skin is sensitive and I don't want him crying anymore." (MCH01, mother; boy aged 2)

\section{Practical realities of maintaining treatment}

Developing a routine

Interviewees discussed the need to develop routines to facilitate scar management at home. Some described how these were embedded in usual day-to-day activities and linked to time at home from school or childcare. This parent who is discussing the routine of PGT and moisturising typifies this type of routine: 
"So typical routine would be he would come home from school, either then or perhaps an hour before bed he would have the [pressure garment] socks off [...] so it was regularly wash the foot every time, and moisturise, then put the Silica gel on, then put the pressure garments on, and then be able to get through for 23 hours, and the next evening take perhaps if he was having his tea for example he would have his socks off. Walk around bare foot for an hour, and he'd have his feet washed, then the cream and the silicone, then it's sock back on again and so forth." (BCP07, father; boy aged 5)

Treatment routines and opportunities to maintain regimes were commonly centred around the morning when getting ready for the day; the evening when getting ready for bed and; for those with smaller children, during nappy changes:

"It was just a case of when you put his nappy on at night and put his pyjamas on, just as you've done his nappy quickly put the Mepiform on and put his trousers on and he's away. Then when you get him changed in the morning before he goes in the bath you just take it off again." (BCP06, Mother; boy aged 1 )

Parents who described established routines also felt that whilst the realities of life may mean that on occasion treatment may not be administered exactly as directed, they could easily get back on track:

"We might have forgotten or come an hour late or something normally, but it was you get him dressed in the morning, you put his patch [returning to] a continuous cycle." (BCP05, father; boy aged 3)

\section{Division of care labour}

Balancing caregiving duties was also discussed as a practical reality of maintaining treatment. For example, work commitments may focus the responsibility for maintaining treatment on a single parent. One mother spoke of feeling emotionally drained trying to keep up with the massage and creaming regime for her son. She found it difficult emotionally to look at the injured area and physically to exert pressure on the skin during massage, but help from her husband was reported as limited due to his work schedule. Division of care labour may threaten adherence and even strain relationships: 
"Every time I remember, but time seems to be running so fast and I am the only one.Dad, every time he comes he will tell me off [...] I am expected to do everything as a magic, and I forget, because I have too much." (BC04, mother; girl aged 6)

Many parents of older children in the sample encouraged them to be actively involved in their own treatment routine which they felt could help to build the child's confidence via observation and awareness of improvements. For younger children, parents spoke more of the role of other care providers in maintaining treatment and the importance of everyone integrating care into their routine:

"My mother in law was involved in that because she does a lot of the day care so we drop him with her in the morning, she takes him to school, so she was putting his patch on of a morning quite often, but she was good because she built it into part of her routine [...] It just fitted in quite naturally actually." (BCP05, father; boy aged 3)

However, parents may also be concerned by the involvement of others in the care routine, such as nursery or school staff, and this was a source of anxiety for some due to concerns about adherence, the reaction of the child to another person giving care to the injured area, and the care of the area itself:

“He's going to nursery in September so I'm a bit like oh God I wish this wasn't happening, I could deal with the pressure vest, but the chin strap and people having to take it off for him and put it on when he's eating. I think about it with germs and things like that, should I leave it until he comes home and then put it on him when he comes home? But the whole point of it is trying to keep it on as long as possible." (MCH01, mother; boy aged 2)

\section{$\underline{\text { Hospital appointments }}$}

Parents also discussed attendance at hospital appointments. Practically this could depend on flexibility in work arrangements and employers, as well as the need to travel distances to specialist burns centres. Some parents had drastically changed arrangements e.g. giving up work to accommodate this. 


\section{Emotional labour involved in the treatment process}

As well as practical realities, there was significant emotional labour involved in developing and maintaining treatment regimes. Parents described attempts to manage their own emotions, as well as those of their child and other family members. A range of impacts were discussed, from depression and anxiety to expressions of guilt and anger related to the accident and injuries. Some parents discussed the use or non-use of counselling services provided by the hospital.

\section{Treatment signification for parents}

A number of parents said that they found it difficult to look at or touch the injured area, or to undertake treatment. For instance, one mother spoke of how the child's father found it difficult to look at their son's injury, so she undertook the massage and creaming. For another family, the father talked about undertaking most of the massage as he was able to exert more pressure, but also because he had more emotional strength in this regard than his wife.

This was often bound up with feelings about what the treatments signified to parents both in terms of the lasting effect on children and personal feelings of blame and guilt related to the accident. For example, one mother described how the pressure garment signified disfigurement and disability to her:

"The initial thing about the pressure garment is as I said it's proving that he's got a disfigurement almost, it's sealing the deal." (BCP01, mother; boy aged 1)

In another interview, the mother, when asked a question specifically referring to pressure garments, immediately reflected back to the burn incident as if thoughts of the treatment could not be explored separately from feelings regarding the circumstances of the accident:

"I should have been there to protect her, 100\%, no mistake, it's my fault." (BC04, mother; girl aged 6)

Perhaps related to this, some parents described attempts to avoid perceived negative judgements about their child or their parenting by covering the scar site or garment under clothing where possible. However, children themselves often had no problem with showing the scar or garment and 
some parents discussed how the realisation of this had forced them to consider and address their own emotions and approach:

"It's taken a while but we've just had to tell ourselves that we're doing everything for him. I always look at it in the perspective of if I can't move on he won't move on [...] I still try to push myself and do what I need to do for him, because if you don't who will?." (BCO2, mother and father; boy aged 4)

Many of the parents spoke of fundamental points during the treatment journey where their child's attitude towards the treatment had forced them to reconsider their own emotions regarding the signification of treatment. For others, it was the realities of maintaining treatment within day-to-day routines that fostered a change in emotion towards the scar management treatment:

"I can't pinpoint when but my mode of thinking changed and got more comfortable, and it was like okay well let's be practical." (BCP01, mother; boy aged 1)

\section{Managing children's emotions}

Further to managing their own emotions, parents also shared details of how they worked to manage the emotions of their child during the scar management treatment process. Many parents spoke of their child's avoidance behaviour; increased clinginess and apprehension of others and; fear and distress during scar management treatment. One mother expressed how the burn incident, treatment and the process of skin healing had affected her son and that previous skin breakage had made him especially nervous even though the skin had now healed well:

"He's lost a fair bit of confidence [...] because we had one occasion where, because the skin breaks easy doesn't it? And the skin broke a little bit, and I think it knocked his confidence a little bit, so he was just a bit worried that if he does anything, because of where it is [...] the skin is always going to break." (BCP02, mother; boy aged 9)

Interestingly, a number of parents spoke about how being in the hospital environment for appointments had a positive influence on their child's behaviour:

"When we go out he's quite clingy, but when we go to the hospital he's walking like he's not scared, he just feels comfortable walking. When he goes into the hospital he is walking 
very... he is walking ahead, and he's just so comfortable. I think he feels this place I feel normal, and when we go out he feels a bit, I don't know, I have noticed this, he's very clingy, and he becomes like he's not so chatty. When he goes to hospital he's so chatty. When we go out [he is] very quiet, and you can see he's scared." (BC01, mother; boys aged 7 and 8 )

In responding to their children's emotions parents were often balancing their own emotional needs with those of their child. Some parents spoke of how they felt overwhelmed by the changes they could perceive in their children, whilst they tried to reassure them about the injury and scarring in age appropriate ways. Some spoke of strategies they employed to try to reduce negative associations with the injury and scar management. One couple whose son became distressed spoke of how they tried to divert his attention:

"Mother: You tell him all sorts of stories don't you? He tells him all sorts of stories, he's fallen off a jet ski and all sorts.

Father: Dragon hunting.

Mother: He knows they're not true, he knows they're just stories." (BC03, mother and father; boy age 3 )

Another mother spoke of trying to equip her child with positive responses to questions and comments from others;

"So I was also trying to get his self-esteem up as well at home, saying, "You're like Superman, and when your friends look at that outfit [his pressure garments] they think wow, because they don't have that outfit, only you have got that outfit," and he would get happy." (BC01, mother; boys aged 7 and 8 )

This mother also spoke of balancing emotions, by giving her son space to vent frustration even if it hurt her emotionally:

"[Child's name] has blamed me when he's been naughty and nasty, he's said [...] "It's your fault," and that's even harder to take, and he doesn't mean it, and he's always apologised after, but because that's hard." (BCP08 mother; boy aged 8) 
Judgements made by parents in responding to their children's emotions persisted throughout the scar management period, including the point at which treatment was coming to an end. Several parents noticed that their children were developing an emotional attachment to pressure garments as they provided a feeling of security whilst wearing them. Some parents were concerned about how their child would manage emotionally when they no longer needed to wear the garments:

"[It will] feel like something was missing, because it became as a part of himself [it needs to be] just the right time maybe." (ECO4, mother; boy aged 2)

Parents also talked about managing the emotions of siblings who may exhibit responses to the burn incident and treatment. For younger siblings in particular, they spoke of increased bed wetting and toilet training regression. The physical and emotional demands of maintaining scar management treatment and emotional wellbeing for themselves and the family were complex and difficult. For those siblings who had more understanding of the situation, some parents described the challenges of being attentive to the needs of all of their children and the anxiety of other children around their sibling's treatment. One couple in particular spoke of their older two children who were traumatised after their sibling's burn incident and the important role that the school had played in helping them to address their distress:

"We spoke to the school and let them know, and the school were extremely nice, even though the headmaster we had there at the time, he would always ask the elder two how is [name of child] if they needed anything they were allowed to speak to anyone or they were allowed to come out of classes and see each other if they needed to." (EC05, father; girl aged 4)

\section{Imagining the future}

A significant influence on parents' attitudes towards scar management in the here and now, were the imagined future consequences for their children. There were two main components to this. Firstly, a desire for optimal scar outcomes based on aesthetic and functional considerations, and, secondly, concerns that children would not have long lasting psychological effects from the incident and subsequent treatments. 
For those parents whose children had no or limited impact on function, they spoke about a desire for the scar area to look as inconspicuous as possible, so as to mediate any potential future anxieties for their child during adolescence and adulthood:

"[The scar] may have no negative effect on his life, but if we can minimise it [...] he might never develop a complex about it and he might always be comfortable about it." (BCP05, father; boy aged 3)

Often views concerning appearance were gendered, with some parents expressing less concern of impact for boys and amplifying fear of this for girls:

"Father: It's not going to be an issue I don't think, he's a boy [...] If he was a girl it would be an issue, but he's a boy." (BCO3, father; boy aged 3)

"At the moment she's quite acceptant of [the scar area], but then obviously when she gets to a teenage girl and things like that I think that's when it will hit her the most, as she gets older." (BCP03 mother; girl aged 6)

However, those parents whose children experienced extensive injuries expressed a stronger desire for them to regain physical and/or cognitive function as an immediate priority over scar appearance. In one interview, a mother whose sons were both badly injured in a house fire explained that she understands that her children may not look the same again. Her concerns for them went beyond aesthetics as her eldest son had amputations requiring further surgery and her younger son was living with brain damage after smoke inhalation:

"Anything that they can do to improve [them] so that they are able to do the things that [they] should be doing at [their] age, that's all that I'm really concerned about." (BC01 mother; boys aged 7 and 8 )

For many interviewees across the spectrum of burn injuries, adopting a positive outlook seemed an important aspect of coping with feelings of uncertainty regarding outcomes:

"I'll face it when it comes, there's no point sitting working myself up for something that might not happen or something that's going to happen, I'll just take it as it comes." (BCP03, mother; girl aged 3) 
Parents also commonly expressed that they hoped that their child would forget the burn incident and scar management. They felt upset about the prospect of children remembering pain or discomfort:

"He's got a very good memory unfortunately, so I think he remembers everything." (EC01, father; boy aged 5)

As such, the emotional investment in the treatment runs deeply. For those children whose scar area improved enough to have minimal or no more contact with the hospital and healthcare professionals, there was a sense of relief that the treatment journey had come to an end. Reflection on their treatment journey often centred on the professionalism of the staff and how grateful parents were for the service that they have received. Both parents and children were glad to say goodbye and often spoke of keeping the pressure garments as mementos of the experience. For some, the reality of no longer having the hospital as a site of safety and the staff as caregivers for them and their child evoked feelings of sadness at the eventual end of the therapeutic relationship that had provided so much support:

"When that finishes that's when I'll be sad [...] so at some point we might not get invited to everything, and then I'll be a bit sad [...] because it's like a little bond sort of thing." (BCP08, mother; boy aged 8)

\section{Negotiating treatment and regime}

For parents' therapeutic role, doing what they see as best for their child whilst meeting clinical requirements required a careful balance of the practical and emotional aspects of scar management. There is a negotiation between the demands of the treatment regime and the practical and emotional realities of parents' treatment journey. As parents gained more confidence and expressed more understanding of how the treatment worked, they could tailor it to meet their child's requirements and fulfil their role as clinical caregiver:

"We've got both cream and strips. We tried the strips and they wouldn't stay on overnight [...] So we put a gel on at night, but we found that the strips, the patches worked very well during the day when he's active, but it's a more standard set of movements, it's not necessarily a lot of rolling in a ball and stretching out big or anything, it's normal 
movements, and even when he's at play and at nursery the patches stay in place." (BCP05, father; boy aged 3)

In another interview, a mother who spoke of her emotional distress at her son's pain and discomfort due to itching explained how a trial and error approach to treatment allowed her to develop a practical solution:

"He went through so many creams because none of them would moisturise his skin properly [...] but now I found that if I mix the Diprobase and the 50:50 it works a lot better than if I was to use one at a time [...] I used to put the cream in the fridge so it cools a bit, and then put it on him, and I found that helped. So it was just a matter of trial and error to be honest." (BC02, mother; boy aged 4)

The outcome of these negotiations can be understood in terms of a treatment evolution from initial rigid adherence to adherence that may become more flexible over time. In some instances, flexible approaches to maintaining treatment were suggested or aided by healthcare professionals who appreciated the need to reconsider regimes. For two of the interviewees, treatment was changed as elements of the regime were impacting negatively on the child's psycho-social development. In both cases, the parents spoke of the difficulties in toilet training children when they were undergoing pressure garment therapy for injuries to the upper thigh and buttock areas. The decision prioritised development over the original treatment and flexible treatment options were suggested and supported by healthcare professionals. In one, treatment was changed to massage and creaming and in the other the pressure garment was modified.

However, in other instances of treatment negotiation, the adoption of flexible adherence was covert, without the knowledge of clinical staff. For example, one mother described her practical and emotional journey in detail expressing feelings of guilt which were exacerbated by her son's apparent relief when he was taken out of his pressure garments. In an effort to negotiate these realities, she explained how a day of not adhering to treatment had become part of their routine and that she had not disclosed this to clinical staff:

"I give him a day's grace, so his day as I said is Saturdays [...] But I have never told anybody at the hospital that [...] just a bit of a break for him [so] that's why I let him have the day where he doesn't have to wear it." (BCP01, Mother; boy aged 1) 
The interview data suggests that while parents felt comfortable in seeking support from healthcare professionals for practical and tangible issues relating to treatment (such as toilet training needs) they may have felt less able to do so for emotional issues.

\section{Discussion}

The set of circumstances that parents and families encounter following burn injury to a child are complex and difficult. Following acute care there is a need for families to negotiate the transition from hospital to home. Scar management therapies such as pressure garments require the adoption of a new aspect to the parenting role; that of therapeutic caregiver. At the same time parents desire some return to normality for their children. Parents' relationship with scar management takes time to develop and results from a complex interplay of the practical realities of scar management and the emotional labour that it entails. The latter is particularly significant for parents who are managing their own emotions and the psychological impact of the burn accident, at the same time as they try to attend to those of the injured child and wider family unit. Some parents manage this and are able to demonstrate strong adherence to treatment advice. The imagined future for their child, for example, as a consequence of negative scar outcomes, influences parental attitudes towards treatment and adherence. However, the practical and emotional realities of treatment are often so significant for families that they adopt flexible approaches to treatment and adherence.

This is the first in-depth qualitative exploration of parents' experiences of scar management therapies to focus explicitly on the factors influencing treatment adherence. We have sampled a diverse range of parents of children aged 0-9, with commonality in the key themes presented across the sample. Whilst we believe this work provides valuable new insights, naturally we are limited to the accounts of those who agreed to take part in this research. There is a possibility that those volunteering to do so may be more likely to be adherent to clinical advice. Whilst there are examples of flexible and non-adherence in this sample we cannot be sure that it is diverse in terms of non-adherent behaviour.

Whilst this is the first qualitative study that has examined parents' experiences of treatment adherence in burn scar management, Santer et al (12) have synthesised the qualitative research evidence relating to non-adherence in long-term medical conditions. There is considerable overlap with the themes that we present here. Factors influencing adherence included caregivers perceptions relating to long term impact and treatment (imagined futures); the difficulties associated with treatment regimens, including child resistance (emotional labour) and impact on the 
family; the desire to preserve normal life (here to regain it following the burn accident); and the relationship with healthcare professionals. However, some themes were evident in our data that were not identified in the Santer (12) systematic review. Firstly, perhaps due to the acute nature of the initial injury and treatment the need for parents to transition from hospital to home was prominent in our data. Additionally, changes in the parenting role and dynamic and specifically the need to adopt a therapeutic caregiver role was also a prominent feature of our data, but was not emphasised in the Santer review. Closely related to this, Horridge et al have explored the ways that parents must adapt to the new realities of life post-burn and how this can impact on children's reintegration into school life (20). They suggest that parental confidence is key to this. In our study it is clear that parents must rapidly adopt a therapeutic caregiver role and develop confidence in their skills to do this, which is sometimes achieved via trial and error. It may be that parents who achieve and / or express more confidence in the clinical caregiver aspect of their parenting role are more successful in findings ways to navigate emotional and practical difficulties in adhering to scar management regimes.

Our data also suggest that whilst parents report very close relationships with clinical staff and place great value in their relationship with them, that they may not always discuss and address issues relating to treatment adherence with staff. This may especially be the case where parents are struggling emotionally to cope with the treatment regime, rather than needing practical advice and support in order to maintain treatment. In the interviews parents sometimes prefaced comments to this effect with phrases such as "I haven't told anyone at the hospital about this ....". Of course we have not observed interactions between patients and staff about the experience of scar management and related adherence to verify these claims. This may be an area for further research; examining how issues relating to the emotional labour involved in scar management and other treatments is dealt with by staff, and in turn how that influences parents' experiences and behaviour related to treatment at home.

A desire to return to 'normality' shaped parents' views of treatment in varied ways. Some felt that pressure garments would facilitate this by providing protection (both physical and emotional), whereas others felt that they signalled difference to other children and may be stigmatising. Regarding the latter, some interviewees found that their children had challenged their own perceptions in this regard and were not necessarily affected by the visibility of garments to others. If this is the case then some discussion of these broader potential benefits of pressure garments (i.e. other than scar related outcomes) during consideration of treatment options could influence 
parents' perspectives on whether they are able to facilitate a return to normality, thereby influencing acceptance and adherence.

We would suggest that there is a need to research further the interactions between burns service staff, parents and children that have the potential to influence views on scar management approaches and potentially adherence to treatment. It may be that simple interventions, including provision of information relating to the typical experience for parents managing scar treatments can facilitate consideration of the key practical and emotional influences on treatment adherence. How staff and burns services manage this at present should be the focus of further research. The emotional labour involved in treatment was particularly prominent in these interviews and was obviously interwoven with the psychological impact of the burn injury for parents. Whilst some interviewees had accessed support services to try to address this there were several examples where interviewees were not receiving support, or had not sought to access it, for example, due to feelings of guilt associated with the accident. Whilst this was not an overt focus of our research we would suggest it is something that needs further attention to support parents and mitigate the psychological morbidity associated with paediatric burn injuries. 


\section{References}

1. Stylianou N, Buchan I, Dunn KW. A review of the international Burn Injury Database (iBID) for England and Wales: descriptive analysis of burn injuries 2003-2011. BMJ Open. 2015;5(2):e006184.

2. Simons M, Price N, Kimble R, Tyack Z. Patient experiences of burn scars in adults and children and development of a health-related quality of life conceptual model: A qualitative study. Burns. 2016;42(3):620-32.

3. Oster C, Hensing I, Lojdstrom T, Sjoberg F, Willebrand M. Parents' Perceptions of Adaptation and Family Life After Burn Injuries in Children. Journal of Pediatric Nursing-Nursing Care of Children \& Families. 2014;29(6):606-13.

4. LeDoux J, Meyer WJ, Blakeney PE, Herndon DN. Relationship between parental emotional states, family environment and the behavioural adjustment of pediatric burn survivors. Burns. 1998;24(5):425-32.

5. Rimmer RB, Bay RC, Alam NB, Sadler IJ, Richey KJ, Foster KN, et al. Measuring the Burden of Pediatric Burn Injury for Parents and Caregivers: Informed Burn Center Staff Can Help to Lighten the Load. Journal of Burn Care \& Research. 2015;36(3):421-7.

6. Piira T, Sugiura T, Champion G, Donnelly N, Cole A. The role of parental presence in the context of children's medical procedures: a systematic review. Child: care, health and development. 2005;31(2):233-43.

7. Thompson R, Boyle D, Teel C, Wambach K, Cramer A. A qualitative analysis of family member needs and concerns in the population of patients with burns. Journal of Burn Care \& Research. 1999;20(6):487-96.

8. Finnerty CC, Jeschke MG, Branski LK, Barret JP, Dziewulski P, Herndon DN. Hypertrophic scarring: the greatest unmet challenge after burn injury. Lancet. 2016;388(10052):1427-36. Epub 2016/10/07.

9. Szabo MM, Urich MA, Duncan $\mathrm{CL}$, Aballay AM. Patient adherence to burn care: A systematic review of the literature. Burns. 2016;42(3):484-91.

10. Martin C, Bonas S, Shepherd L, Hedges E. The experience of scar management for adults with burns: An interpretative phenomenological analysis. Burns. 2016;42(6):1311-22.

11. Ripper S, Renneberg B, Landmann C, Weigel G, Germann G. Adherence to pressure garment therapy in adult burn patients. Burns. 2009;35(5):657-64.

12. Santer M, Ring N, Yardley L, Geraghty AWA, Wyke S. Treatment non-adherence in pediatric long-term medical conditions: systematic review and synthesis of qualitative studies of caregivers' views. Bmc Pediatrics. 2014;14:10.

13. Phillips C, Fussell A, Rumsey N. Considerations for psychosocial support following burn injury - A family perspective. Burns. 2007;33(8):986-94.

14. ISRCTN Registry. A feasibility study and open pilot two-arm randomised controlled trial comparing Pressure Garment Therapy with no Pressure Garment Therapy for the prevention of abnormal scarring after burn injury. BioMed Central; 2014 [3rd March 2017]; Available from: http://www.isrctn.com/ISRCTN34483199.

15. National Institute for Health Research. HTA - 12/145/04: A feasibility study and open pilot two-arm randomised controlled trial comparing Pressure Garment Therapy with no Pressure Garment Therapy for the prevention of abnormal scarring after burn injury (PEGASUS). 2013 [3rd March 2017]; Available from: http://www.nets.nihr.ac.uk/projectsOld/hta/1214504.

16. Dicicco-Bloom B, Crabtree BF. The qualitative research interview. Med Educ. 2006;40(4):314-

17. Braun V, Clarke, V. Successful Qualitative Research: a practical guide for beginners. Thousand Oaks, CA: Sage; 2013.

18. Malterud K, Siersma VD, Guassora AD. Sample Size in Qualitative Interview Studies: Guided by Information Power. Qual Health Res. 2015.

19. Braun V, Clarke, V. . Using thematic analysis in psychology. Qual Res Psychol. 2006;3:77-101. 
20. Horridge G, Cohen K, Gaskell S. BurnEd: Parental, psychological and social factors influencing a burn-injured child's return to education. Burns. 2010;36(5):630-8. 